\title{
Qualitative zoning of groundwater for drinking purposes in Lenjan plain using GQI method through GIS
}

\author{
Amin Mohebbi Tafreshi ${ }^{1}$, Ghazaleh Mohebbi Tafreshi ${ }^{{ }^{*}}$ \\ ${ }^{1}$ Young Researchers and Elite Club, Science and Research Branch, Islamic Azad University, Tehran, Iran
}

\begin{abstract}
Background: A new method has been presented specifically for zoning the quality of groundwater for drinking purposes; this method is the groundwater quality index (GQI) method. The present research used the GQI method to qualitatively zoning of the Lenjan groundwater for drinking purposes.

Methods: Three phases were applied in this research. In the first phase, working on the quality data of 38 wells within the studied plain, the raster map of quality concentration parameters, including $\mathrm{pH}$, TDS, $\mathrm{Cl}, \mathrm{SO}_{4}, \mathrm{Ca}, \mathrm{Mg}$, and $\mathrm{Na}$ parameters, was provided by interpolation using the kriging method in the ArcGIS software. In the second phase, the mentioned maps were standardized so that various bits of data can follow a common standard and scale. In the third phase, weight was applied to each standardized map, and ultimately the classification map for each parameter was drawn. The final GQI map was created by combining the mentioned classification maps.

Results: The GQI values for Lenjan plain were rated from the minimum (67.48) to the maximum (90.05). The results showed an average to acceptable level of quality for drinking water.

Conclusion: According to the final map, the central and southern parts of Lenjan plain, which have acceptable GQI rankings, are the best zones from which to use groundwater for drinking purposes. Keywords: Drinking water, GQI, Groundwater, Lenjan, Water quality index, Water quality, Water wells Citation: Mohebbi Tafreshi A, Mohebbi Tafreshi G. Qualitative zoning of groundwater for drinking purposes in Lenjan plain using GQI method through GIS. Environmental Health Engineering and Management Journal 2017; 4(4): 209-215. doi: 10.15171/EHEM.2017.29.
\end{abstract}

\section{Article History:}

Received: 3 June 2017 Accepted: 29 August 2017 ePublished: 18 September 2017

\section{Introduction}

Due to the shortage of surface water, Iran's groundwater resources (as in many other countries with dry and semidry climates) have become the most important and reliable source of water. Thus, it is necessary to consider the quality of this resource for drinking purposes. In recent years, industrial development and the use of modern methods in agriculture, such as using different types of fertilizers and chemical poisons, have led to the contamination of groundwater and a decrease in the quality of this valuable resource. Decontaminating groundwater is an extremely costly and time-consuming task. Contamination is detected in a phase in which it is almost impossible to reverse the damage; therefore, the best solution is prevention. The first step of prevention is to measure the concentration of contaminants in order to find a management solution to the problem. Schoeller's quality-classification diagram is a method is widely used to estimate the contamination of groundwater used for drinking. This diagram estimates the quality of drinking water in point sources (shafts, fountains, and aqueducts) and identifies the best resource based on quality among other point sources. Many studies use this method to determine the quality of drinking water (1-4). In spite of the advantages to estimating the quality of groundwater resources with this method, it is impossible to examine an entire area so as to draw a zoning map of the condition of groundwater for drinking purposes. Another restriction of this method is the limited number of water quality parameters. For zoning and estimating groundwater quality, many water quality indexes have been developed in recent years (5-11). One of these methods is the groundwater quality index (GQI) method for drinking water that has been employed in the present study. In this method offered by Babiker et al (12), the chemical parameters affecting the quality of drinking water are normalized, indexed, and compared to the World Health Organization (WHO) standards and guidelines. After the assimilation of these parameters, a zoning map of drinking water quality is created using the geographic information system. In recent years, this method has become well-known, and numerous studies have attempted to use it (13-22). The purpose of the current study was to investigate and zoning the quality of groundwater for drinking purposes in Lenjan plain (Iran) 
using the GQI method.

\section{Methods}

Study area

Lenjan plain (49611N-575446N and 3522155E-3592252E) with an area of 1588 square $\mathrm{km}$ is located in the $39 \mathrm{~N}$ zone (according to the UTM coordinate system), the center of Iran (Isfahan province), in the Sanandaj-Sirjan structural zone (23). This region has average annual rainfalls of 200 $\mathrm{mm}$ (in the northern section) to $300 \mathrm{~mm}$ (in the center and southern sections) and average annual temperatures of $12^{\circ} \mathrm{C}$ (in the northern section) to $8^{\circ} \mathrm{C}$ (in the central and southern sections), and it can be classified as having a cold and desert dry climate (according to De Martonne's classification). The groundwater stream in Lenjan plain stretches from southwest and northeast to the center and exits from the north (Figure 1).

\section{Data collection and preparation}

To examine the quality of groundwater in the studied plain, the qualitative statistics (from 2015) of 38 wells were used (Figure 2) and included the parameters $\mathrm{Na}, \mathrm{Mg}, \mathrm{Ca}$, TDS, $\mathrm{SO}_{4}, \mathrm{Cl}$, and $\mathrm{pH}$. This study used the GQI method to classify water for drinking purposes. Sampling was done based on the guidelines of the US Environmental Protection Agency (EPA) (24). The samples were taken and stored in acid-washed polyethylene bottles. The

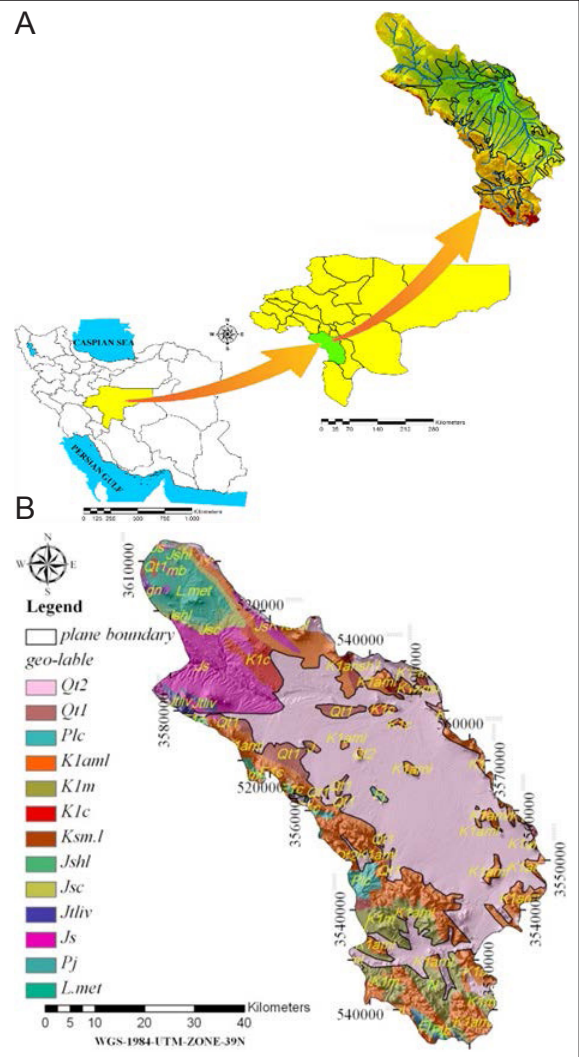

Figure 1. Location (A) and geology map of the studied area (B). collected samples were filtered using a $0.45 \mu \mathrm{m}$ acetate cellulose filter on site and kept at a temperature below $4^{\circ} \mathrm{C}$. Testing was conducted less than 24 hours after sampling at the Central Laboratory of Isfahan Province Water and Wastewater Company and based on the methods of the American Public Health Association. Field parameters such as $\mathrm{pH}$ were measured in the field using portable meters. $\mathrm{Ca}^{2+}$ and $\mathrm{Mg}^{2+}$ were determined using the standard EDTA titration method, and sodium was analyzed by flame photometry. The bicarbonate ion concentration was determined by acid titration, while the chloride concentration was determined by $\mathrm{AgNO}_{3}$ titration and the sulfate concentration was analyzed using the turbidity meter.

This study performed groundwater quality zoning for drinking purpose using the GQI method through three phases as described below.

First phase

The concentration raster maps of the quality parameters were drawn using the kriging interpolation method in ArcGIS. Kriging is a method of interpolation based on a weighted moving average that uses known values to determine unknown values. This method is the best linear unbiased estimator (25).

In kriging, the estimated value, $Z$, at any point $X_{0}$ is given as follows:

$$
Z *\left(X_{0}\right)=\sum_{i-1}^{n} \lambda_{i} Z\left(X_{i}\right)
$$

Where $\lambda_{i}$ is the weight for the known value $Z$ at location $X_{i}$. The kriging weights of ordinary kriging fulfill the unbiasedness condition.

$\sum_{i-1}^{n} \lambda_{i}=1$

First, an experimental semivariogram has to be calculated using the following equation:

$\gamma^{*}(h)=\frac{1}{2 N(h)} \sum_{i=1}^{N(h)}\left[Z\left(X_{i}\right)-Z\left(X_{i}+h\right)\right]^{2}$

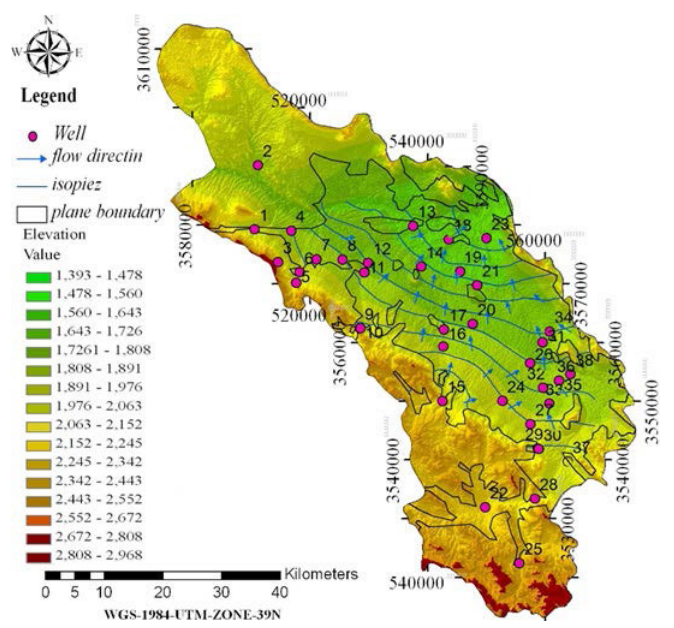

Figure 2. Location of sampling wells and groundwater flow direction of the studied area 
where $\gamma^{*}(h)$ is the estimated value of the semivariance for lag class $h ; \mathrm{N}(\mathrm{h})$ is the number of experimental pairs separated by a vector $h$ of that lag class; and $Z\left(X_{i}\right)$ and $Z\left(X_{i}\right.$ $+h)$ are values of variable $\mathrm{z}$ at $X_{i}$ and $X_{i}+h$, respectively. When the experimental semivariograms are calculated, suitable theoretical models are fitted to them, and the best model is selected based on the lowest RSS value and used in the kriging procedure.

Second phase

The correlation between the WHO standard for each parameter of drinking water and the concentration map of the same parameter is determined through normalized maps with the same scale through equation 4 :

$C(X)=\frac{x^{\prime}-x}{x^{\prime}+x}$

where $x$ is the allowed number according to the WHO standard (26), $x^{\prime}$ is the concentration raster map of each groundwater quality parameter, and $C(X)$ is the correlative index map of the quality parameter $X$ the pixel values of which vary between -1 and +1 . In this map, the more pixel values tend toward -1 , the higher the quality of water upon quality parameter $X$. This shows that the quality is somehow close to the WHO standard (26). Those pixel values tending more toward +1 show decrease quality, which means that the quality is far from the WHO standard (26) for this parameter.

\section{Third phase}

Each correlation index map is ranked between 1 and 10 in order to set the rank map for each quality parameter. Ranked maps show the critical zones of the aquifer in relation to each quality parameter. To rank each pixel on the rank map, equation 5 is used:

$r(X)=0.5 \times(C(X))^{2}+4.5 \times C(X)+5$

On this map, the pixels approaching closer to 1 indicate that the groundwater quality to quality parameter $X$ is proper and that, based upon this parameter, the quality is close to the WHO standard (26). When values tend more toward 10, a decrease in water quality exists, and its quality is far from the WHO standard (26) concerning the related parameter.

At the end of the phase 3, the weight of each parameter is extracted by averaging the minimum and maximum numbers on the rank map of the same parameter. Then, using equation 6 , quality zoning will be done through the GQI method.

$$
G Q I=100-\left(\frac{(r(X 1) w(1)+r(X 2) w(2)+\ldots+r(X m) w(m)}{n}\right.
$$

In equation $6, r(X 1)$ to $r(X m)$ indicates the rank map of quality parameter 1 to $\mathrm{m}$, and $\mathrm{w}$ to $w(m)$ shows the weight of quality parameter 1 to $\mathrm{m}$; $\mathrm{n}$ is the number of quality parameters used.

On the final map, a higher quality of groundwater for
Table 1. Water quality classification using GQI method

\begin{tabular}{lc}
\hline Quality & GQI \\
\hline Good & $91-100$ \\
Acceptable & $71-90$ \\
Medial & $51-70$ \\
Poor & $26-50$ \\
Very unpleasant & $0-25$ \\
\hline
\end{tabular}

drinking purposes is reached when the pixel value tends more toward 100 . When tending to 0 , it then indicates a worse quality of groundwater for drinking purposes. Water quality classification using the GQI method is shown in Table 1.

Results

Table 2 shows the values of the quality parameters of Lenjan plain and the value allowed for each parameter (except $\mathrm{pH}$ that has no unit, all other parameters are reported in $\mathrm{mg} / \mathrm{L}$ ) according to the WHO standards (26). As seen in this table, the only parameter which has a maximum value in groundwater lower than the WHO standard (26) is $\mathrm{Mg}$; the maximum values of all other parameters, especially $\mathrm{Na}, \mathrm{TDS}, \mathrm{SO}_{4}$, and $\mathrm{Cl}$, are higher than the WHO standards (26). This shows the existence of points in which these parameters are in bad condition. Figure 3 shows the interpolated maps of drinking water parameters. As can be seen, most parameters reveal high levels of anomalies in the northern parts of the plain. These anomalies can be attributed to the metamorphic conglomerate as well as the sediment structures upstream from the groundwater streams, since the salts existing in these structures have entered the groundwater streams because of erosion, thus increasing groundwater salinity. Furthermore, it may have occurred due to placing in the urban zone.

After drawing the interpolated raster maps of the quality values using equation 4 in the spatial analysis section of ArcGIS, correlation index maps of quality parameters were created. As indicated in Table 3 and Figure 4, on all maps except for the index map for $\mathrm{Mg}$, the northern section and at the output of the studied plain, the pixel values tending toward +1 , which shows an inappropriate quality because of its distance from the WHO standard (26).

As indicated in Table 4 and Figure 4, on the rank maps of the quality parameters which were drawn using equation 5 in the spatial analysis section of ArcGIS, the maximum variation range belonged to the quality parameter $\mathrm{Cl}$ (minimum rank: 1.32; maximum rank: 8.87) and the minimum variation range belonged to the quality parameter $\mathrm{pH}$ (minimum rank: 4.96; maximum rank: 5.16). The high anomaly of $\mathrm{Cl}$ on these maps is related to the great range of metamorphosed structures, particularly the green schist containing $\mathrm{Cl}$ and sediments containing $\mathrm{Cl}$ in the northwestern section and, consequently, a decrease in $\mathrm{Cl}$. 
Table 2. Value and statistics of the qualitative parameters and the allowed value of each parameter according to WHO standards in wells of the studied area

\begin{tabular}{|c|c|c|c|c|c|c|c|}
\hline Parameter & $\mathrm{SO}_{4}{ }^{2-}$ & $\mathrm{Cl}^{-}$ & $\mathrm{Na}^{+}$ & $\mathrm{Mg}^{2+}$ & $\mathrm{Ca}^{2+}$ & PH & TDS \\
\hline w1 & 86.88 & 39.05 & 25.30 & 28.80 & 56 & 8.10 & 417 \\
\hline w2 & 490.10 & 262.70 & 209.30 & 68.40 & 102 & 8.10 & 1414 \\
\hline w3 & 101.30 & 145.55 & 73.60 & 19.20 & 76 & 8.20 & 537 \\
\hline w4 & 317.30 & 17.75 & 172.50 & 28.80 & 12 & 8.70 & 714 \\
\hline w5 & 336.50 & 49.70 & 207 & 22.80 & 26 & 8.60 & 917 \\
\hline w6 & 53.28 & 28.40 & 23 & 19.20 & 44 & 8.10 & 338 \\
\hline w7 & 216.50 & 56.80 & 69 & 30 & 74 & 8 & 619 \\
\hline w8 & 43.68 & 21.30 & 20.70 & 14.40 & 42 & 8.30 & 296 \\
\hline w9 & 125.30 & 17.75 & 27.60 & 20.40 & 34 & 8.50 & 279 \\
\hline w10 & 82.08 & 10.65 & 29.90 & 3.60 & 44 & 8.50 & 234 \\
\hline w11 & 393.60 & 106.50 & 218.50 & 15.60 & 46 & 8.50 & 863 \\
\hline w12 & 576 & 106.50 & 253 & 39.60 & 54 & 8.40 & 1163 \\
\hline w13 & 1018 & 2201 & 736 & 96 & 880 & 8 & 5649 \\
\hline w14 & 523.20 & 411.80 & 271.40 & 50.40 & 164 & 8.10 & 1547 \\
\hline w15 & 58.08 & 42.60 & 23 & 13.20 & 44 & 8.40 & 302 \\
\hline w16 & 134.90 & 46.15 & 36.80 & 21.60 & 80 & 7.80 & 466 \\
\hline w17 & 595.70 & 71 & 204.70 & 37.20 & 110 & 8 & 1118 \\
\hline w18 & 1219 & 1775 & 591.10 & 228 & 640 & 8 & 5152 \\
\hline w19 & 744.50 & 177.50 & 138 & 76.80 & 192 & 7.90 & 1407 \\
\hline w20 & 96 & 74.55 & 59.80 & 16.80 & 52 & 8.10 & 426 \\
\hline w21 & 197.30 & 156.20 & 87.40 & 30 & 94 & 8 & 789 \\
\hline w22 & 43.68 & 28.40 & 11.50 & 14.40 & 40 & 8.40 & 248 \\
\hline w23 & 1032 & 795.20 & 577.30 & 86.40 & 248 & 8.20 & 2884 \\
\hline w24 & 341.30 & 56.80 & 78.20 & 48 & 72 & 8.30 & 725 \\
\hline w25 & 29.28 & 10.65 & 4.60 & 14.40 & 32 & 8.40 & 194 \\
\hline w26 & 715.70 & 113.60 & 269.10 & 42 & 102 & 8.30 & 1435 \\
\hline w27 & 379.70 & 35.50 & 158.70 & 25.20 & 54 & 8.50 & 794 \\
\hline w28 & 62.88 & 24.85 & 13.8 & 20.40 & 34 & 8.40 & 261 \\
\hline w29 & 192.50 & 35.50 & 64.40 & 20.40 & 60 & 8.30 & 456 \\
\hline w30 & 202.10 & 28.40 & 52.90 & 25.20 & 50 & 8.30 & 414 \\
\hline w31 & 562.10 & 241.40 & 207 & 88.80 & 104 & 8.10 & 1428 \\
\hline w32 & 437.30 & 71 & 209.30 & 28.80 & 48 & 8.40 & 897 \\
\hline w33 & 197.30 & 42.60 & 69 & 30 & 70 & 8.30 & 566 \\
\hline w34 & 355.70 & 383.40 & 230 & 73.20 & 94 & 8.40 & 1414 \\
\hline w35 & 216.50 & 88.75 & 66.70 & 34.80 & 66 & 8.20 & 555 \\
\hline w36 & 523.20 & 106.50 & 186.30 & 40.80 & 92 & 8.30 & 1038 \\
\hline w37 & 96.48 & 67.45 & 32.20 & 33.60 & 40 & 8.50 & 413 \\
\hline w38 & 187.70 & 60.35 & 59.8 & 36 & 70 & 8.60 & 575 \\
\hline WHO standard & 250 & 250 & 200 & 300 & 300 & 8 & 1000 \\
\hline Arithmetic average & 341.68 & 210.80 & 151.80 & 40.61 & 109 & 8.27 & 1024.80 \\
\hline Standard deviation & 300.04 & 452.10 & 167.40 & 38.71 & 164.54 & 0.21 & 1174.40 \\
\hline Maximum & 1219.20 & 2201 & 736 & 228 & 880 & 8.70 & 5649 \\
\hline Minimum & 29.28 & 10.65 & 4.60 & 3.60 & 12 & 7.80 & 194 \\
\hline Median & 216.48 & 63.90 & 75.90 & 29.40 & 63 & 8.30 & 666.50 \\
\hline Skew & 1.29 & 3.64 & 2.05 & 3.36 & 3.87 & -0.14 & 3.01 \\
\hline
\end{tabular}

In the last phase of the GQI method, the weight of each parameter is calculated in order to merge the layers. The weight of each parameter on the rank map of the same parameter was calculated by averaging the maximum and minimum numbers. These are indicated in Table 4. According to this table, the highest weight belongs to the quality parameter TDS with a value of 5.29, and the lowest belongs to the quality parameter $\mathrm{Mg}$ with a value of 2.76 .

\section{Discussion}

Eventually the groundwater quality zonation map of Lenjan plain using the GQI method was created by merging the quality parameters rank maps. According to the map (Figure 4), the value of GQI was between a minimum of 67.48 and a maximum of 90.05 . To sum up, the results of this study indicated that the quality of the drinking water in the studied area could be classified as 


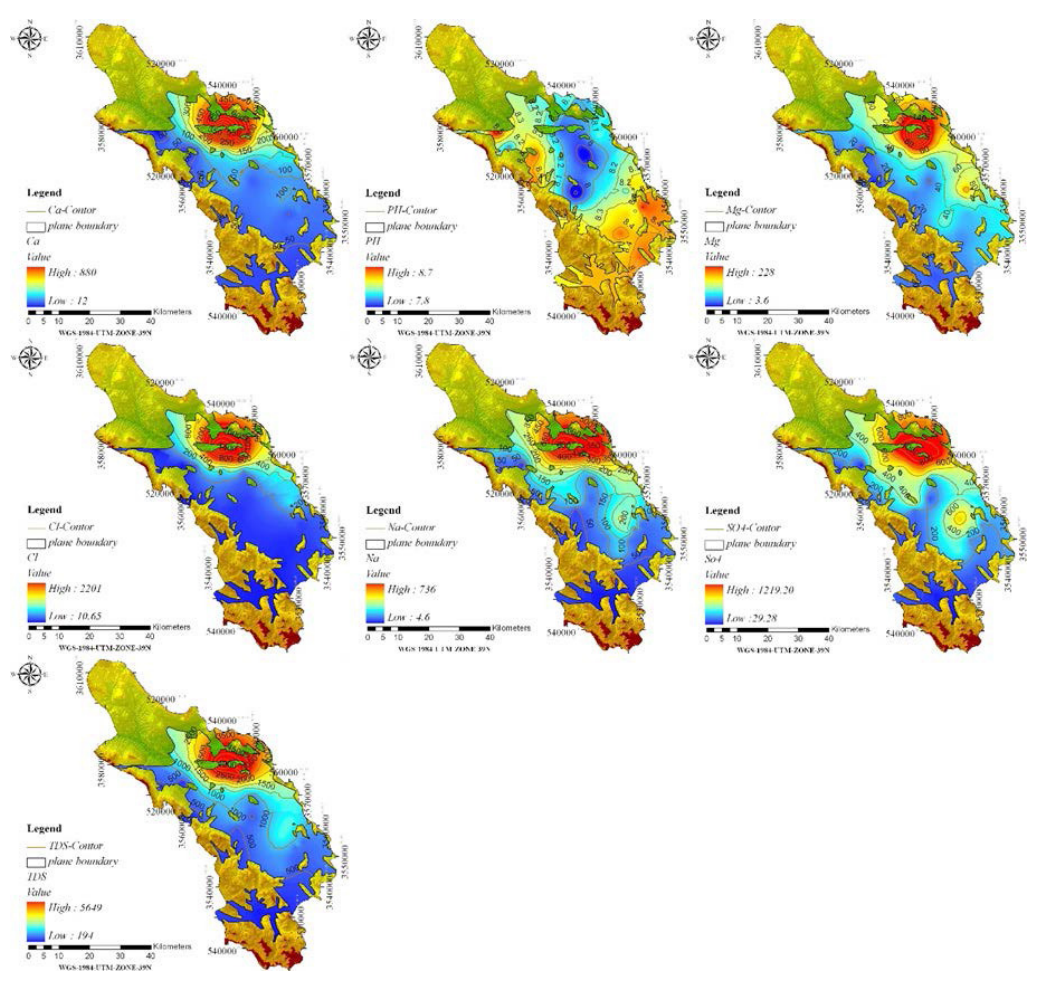

Figure 3. Interpolate drinking water parameters by kriging method.

Table 3. Statistical parameters of correlation index map

\begin{tabular}{lcc}
\hline Parameter & Minimum & Maximum \\
\hline $\mathrm{C}(\mathrm{Ca})$ & -0.91 & 0.48 \\
$\mathrm{C}(\mathrm{Cl})$ & -0.90 & 0.79 \\
$\mathrm{C}(\mathrm{Na})$ & -0.94 & 0.56 \\
$\mathrm{C}(\mathrm{Mg})$ & -0.95 & -0.14 \\
$\mathrm{C}(\mathrm{pH})$ & -0.008 & 0.036 \\
$\mathrm{C}(\mathrm{SO} 4)$ & -0.77 & 0.65 \\
$\mathrm{C}(\mathrm{TDS})$ & -0.66 & 0.69 \\
\hline
\end{tabular}

Table 4. Statistical parameters of rank map and weight calculations of qualitative parameters

\begin{tabular}{llll}
\hline Parameter & Minimum & Maximum & Weight (Mean) \\
\hline $\mathrm{r}(\mathrm{Ca})$ & 1.28 & 7.27 & 4.28 \\
$\mathrm{r}(\mathrm{Cl})$ & 1.32 & 8.87 & 5.10 \\
$\mathrm{r}(\mathrm{Na})$ & 1.18 & 7.70 & 4.44 \\
$\mathrm{r}(\mathrm{Mg})$ & 1.14 & 4.37 & 2.76 \\
$\mathrm{r}(\mathrm{pH})$ & 4.96 & 5.16 & 5.06 \\
$\mathrm{r}(\mathrm{SO} 4)$ & 1.81 & 8.18 & 5.00 \\
$\mathrm{r}(\mathrm{TDS})$ & 2.22 & 8.36 & 5.29 \\
\hline
\end{tabular}

medial (in the northern parts of the plain) to acceptable. The findings of the current study are similar to those of Jokar et al (27) who used the GQI method to study Ahu-dasht plain in Khuzestan (southwestern Iran) for groundwater quality zoning. Their study showed a minimum level of 66 to a maximum of 84 for GQI in different parts of the plain; therefore, the groundwater quality was rated as average to acceptable.

Jodavi (28) studied the groundwater quality for drinking purposes in Feyz-abad plain (in northeastern Iran) using the GQI index for drinking water quality zoning. Their results showed a minimum level of 92 and a maximum of 94 for GQI.

Mir Arabi et al (29) also used the GQI method for drinking water quality zoning in the Abarkuh plain in Yazd province (central Iran). Their results showed that according to the estimated GQI, the drinking water quality was rated as average.

In another study done by Rahmani et al (30), the groundwater quality in Izeh plain (southwestern Iran) was assessed for drinking. The results showed GQI =92; thus, it was concluded that the groundwater quality is proper. Afzali et al (20) used the GQI method to assess groundwater quality in Haraz Alluvial fan. The investigation of water samples using the GQI method showed that the water quality in the study area (in terms of the indicator) ranged from moderate to good (71.83-82.26).

Geologic and GQI maps show that the water with the lowest quality was in the northern section and at the output of the studied plain. Possible explanations for this could be related to the long distance traveled by the groundwater, low sedimentation, concentration of the geological textures and structures in these areas. These possible explanations are similar to the findings of Kheiry and Khademi (17) and Mohebbi Tafreshi et al (16). 


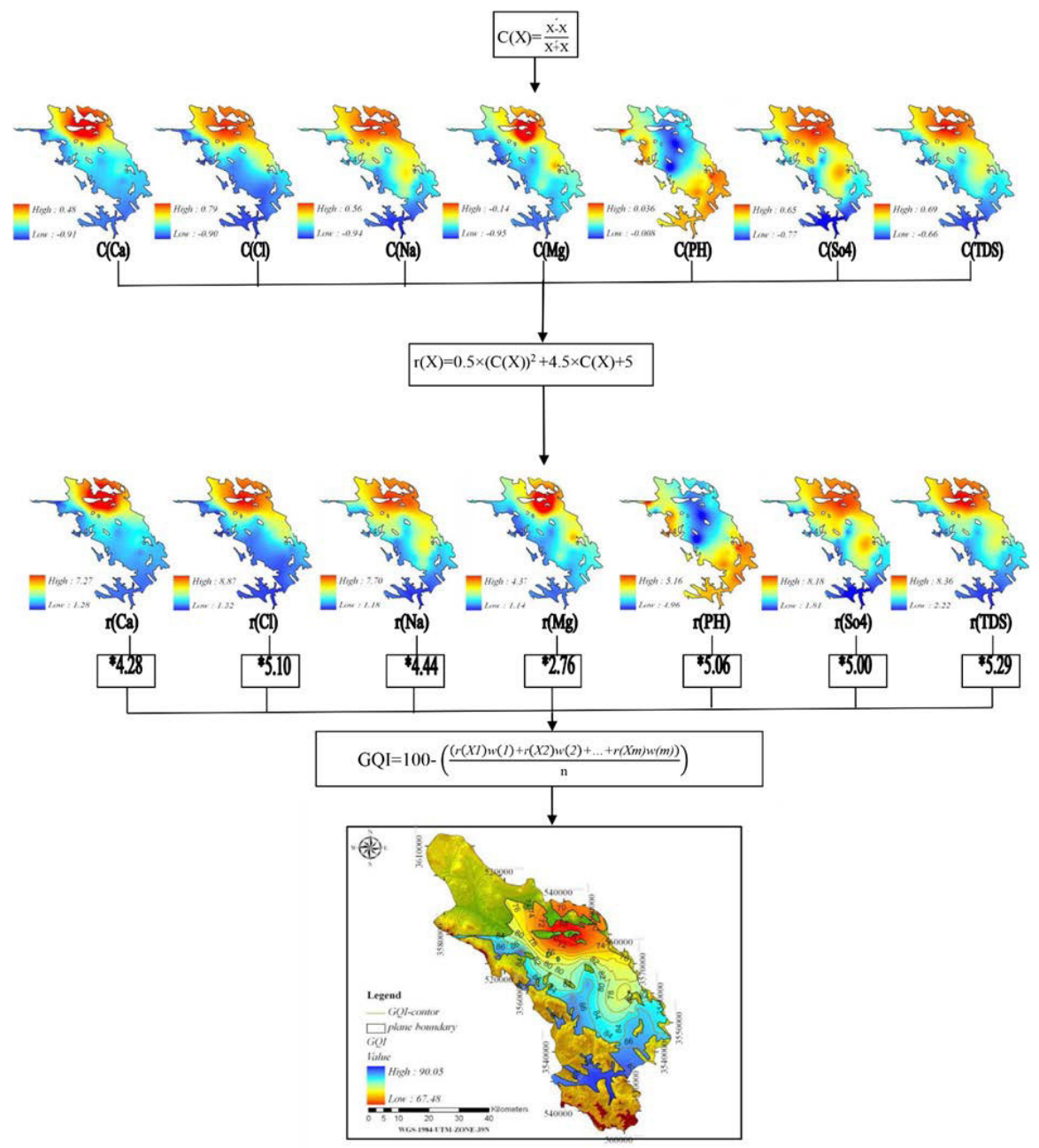

Figure 4. Various stages of GQI method.

\section{Conclusion}

According to the spatial variability of different pollutants, qualitative zoning of groundwater is the first and most crucial step in water management measures. Zoning aims at identifying the qualitative features of groundwater in order to make appropriate decisions concerning the use or disuse of water resources in the required applications. This study used the GQI method (a GIS-based method) to qualitative zoning of groundwater.

The results obtained by analyzing the effective parameters on drinking water quality showed that the quality of the groundwater samples taken from the studied area based on the GQI method could be classified as medial (in the northern parts of the plain) to acceptable (in the central and southern parts of the plain) for drinking purposes. The model used in this work was based on using GIS, the GQI method, and drinking water parameters, and it is a good approach to qualitative zoning groundwater for drinking proposes. It extends the existing methods of this field in terms of groundwater management.

\section{Acknowledgments}

The authors are thankful to the Isfahan Regional Water
Authority and Kharazmi University for providing the facilities necessary to carry out this work.

\section{Ethical issues}

The authors confirm that this manuscript is their original work and has not been published nor is under review in any other refereed journal, and it is not being submitted for publication elsewhere.

\section{Competing interests}

The authors declare that they have no competing interests.

\section{Authors' contributions}

All authors contributed equally and participated in the collection, analysis and interpretation of the data. All authors critically reviewed, refined and approved the manuscript.

\section{References}

1. Gemici U, Tarcan G. Hydrogeological and hydrogeochemical features of the Heybeli Spa, Afyon, Turkey: arsenic and the other contaminants in the thermal waters. Bull Environ Contam Toxicol 2004; 72(6): 1107-14. 
2. Baghvand A, Nasrabadi T, Nabi Bidhendi GR, Vosoogh A, Karbassi A, Mehrdadi N. Groundwater quality degradation of an aquifer in Iran central desert. Desalination 2010; 260(1): 264-75. doi: 10.1016/j.desal.2010.02.038.

3. Hosseinifard SJ, Mirzaei Aminiyan M. Hydrochemical Characterization of Groundwater Quality for Drinking and Agricultural Purposes: A Case Study in Rafsanjan Plain, Iran. Water Qual Expo Health 2015; 7(4): 531-44. doi: 10.1007/s12403-015-0169-3.

4. Nabi Bidhendi GR, Karbassi AR, Nasrabadi T, Hoveidi $\mathrm{H}$. Influence of copper mine on surface water quality. Int J Environ Sci Technol (Tehran) 2007; 4(1): 85-91. doi: $10.1007 / \mathrm{bf03325965.}$

5. Kourgialas NN, Karatzas GP. Groundwater contamination risk assessment in Crete, Greece, using numerical tools within a GIS framework. Hydrological Sciences Journal 2015; 60(1): 111-32. doi: 10.1080/02626667.2014.885653.

6. Dokou Z, Kourgialas NN, Karatzas GP. Assessing groundwater quality in Greece based on spatial and temporal analysis. Environ Monit Assess 2015; 187(12): 774. doi: 10.1007/s10661-015-4998-0.

7. Sobhanardakani S, Taghavi L, Shahmoradi B, Jahangard A. Groundwater quality assessment using the water quality pollution indices in Toyserkan Plain. Environmental Health Engineering and Management Journal 2017; 4(1): 21-7. doi: 10.15171/ehem.2017.04.

8. Kourgialas NN, Karatzas GP, Koubouris GC. A GIS policy approach for assessing the effect of fertilizers on the quality of drinking and irrigation water and wellhead protection zones (Crete, Greece). J Environ Manage 2017; 189: 150-9. doi: 10.1016/j.jenvman.2016.12.038.

9. Pourkhosravani M. Qualitative analysis of Orzooiyeh plain groundwater resources using GIS techniques. Environmental Health Engineering and Management Journal 2016; 3(4): 209-15. doi: 10.15171/ehem.2016.21.

10. Yari AR, Sobhanardakani S. Water Quality Assessment of Groundwater Resources in Qaleeh Shahin Plain Based on Cd and HEI. Int Arch Health Sci 2016; 3(3): 101-106. doi: 10.18869/IAHS.3.3.101.

11. Kouli M, Lydakis-Simantiris N, Soupios P. GIS-Based aquifer modeling and planning using integrated geoenvironmental and chemical approaches. In: Groundwater Modeling Management. Nova Science Publishers, Inc; 2011.

12. Babiker IS, Mohamed MAA, Hiyama T. Assessing groundwater quality using GIS. Water Resources Management 2007; 21(4): 699-715. doi: 10.1007/s11269006-9059-6.

13. El-Fadel M, Tomaszkiewicz M, Abou Najm M. Sustainable coastal aquifer management in urban areas: The role of groundwater quality indices. 4th Global Forum on Urban Resilience and Adaption, Proceedings of the Resilient Cities 2013 Congress; 2013 May-Jun 31-32; Bonn; 2013. [In Persian].

14. Nikpeyman V, Mohammadzadeh H. Assess spatial variations of Mashhad groundwater quality using GQI. First Conference on Exploration Engineering of Underground Resources; 2013 Dec 10-11; Shahrood; 2013. [In Persian].

15. Azizi F, Mohammadzadeh H, Abdollahi Mansourkhani M. Assess the spatial variation of Jafar Zadeha quifer groundwater quality using GWQI. Water Flow and Pollution National Conference; 2012 Apr 21-22; Tehran; 2012. [In Persian].

16. Mohebbi Tafreshi A, Kheirkhah zarkesh MM, Mohebbi Tafreshi G. An examination and qualitative zoning of groundwater for drinking purposes in Golpayegan plain by GQI method using GIS. Third National Conference on Comprehensive Water Resources Management; 2012 Sep 10-11; Sari; 2012. [In Persian].

17. Kheiry H, Khademi S. Application GQI in assessing the water quality of Noshahr - Noor for drinking. 7th Conferences of Iran Society of Economic Geology; 2015 Sep 9-10; Damghan; 2015. [In Persian].

18. Alexander AC, Ndambuki J, Salim R, Manda A. Assessment of Spatial Variation of Groundwater Quality in a Mining Basin. sustainability 2017; 9(5): 1-14. doi: 10.3390/ su9050823.

19. Otari M, Dabiri R. Assessment of anthropogenic activities on the water quality of froumad plain based on qualitative indicators. Iranian Journal of Earth Sciences 2015; 7(1): 1424.

20. Afzali A, Shahedi K, Habib Nezhad Roshan M, Solaimani K, Vahabzadeh G. Groundwater quality assessment in Haraz Alluvial fan, Iran. Int J Sci Res Environ Sci 2014; 2(10): 34660. doi: 10.12983/ijsres-2014-p0346-0360.

21. Tomer T. Water quality indices used for groundwater quality assessment. Int J Res Environ Sci Technol 2015; 5(3): 76-80.

22. Krishnaraj S, Kumar S, Elango KP. Spatial Analysis of Groundwater Quality Using Geographic Information System - A Case Study. IOSR Journal of Environmental Science, Toxicology and Food Technology 2015; 9(2): 1-6. doi: 10.9790/2402-09230106.

23. Aqanabati A. Geology of Iran. Tehran: Geological Survey of Iran; 2013. [In Persian].

24. Vail J, France D, Lewis B. Groundwater Sampling. Athens, Georgia: U.S. Environmental Protection Agency (USEPA); 2013.

25. Webster R, Oliver MA. Geostatistics for Environmental Scientists. Chichester: John Wiley; 2001.

26. World Health Organization (WHO). Guidelines for Drinking-Water Quality. 4th ed. Geneva, Switzerland: WHO; 2011.

27. Jokar K, Kalantari N, Rahimi M, Rahmani G, Jokar E. Quality assessment of Ahudasht aquifer using GQI. 4th Iran Water Resources Management Conference; 2011 May 3-4; Tehran; 2011. [In Persian].

28. Jodavi A. GQI introduction for the assessment of ground water quality for drinking purposes. 27th National Congress Geology and 13th National Congress geological society of Iran; 2010 Feb 8-10; Tehran; 2010. [In Persian].

29. Mir Arabi A, Jamali M, Mahmoudi S, Ghodrat M. Qualitative zoning of drinking water with using quality index in GIS. Approach the water with clean water National Conference; 2011 March 2-3; Tehran; 2011. [In Persian].

30. Rahmani G, Chitsazan M, Zare Sefat M, Kalantari N. Ground Water Quality assessment of Izeh Piun plain using GQI index for drinking purposes. 4th National Conference Water Resources Management; 2011 May 3-4; Tehran; 2011. [In Persian]. 